Check for updates

Cite this: RSC Adv., 2017, 7, 26328

\title{
Temperature controlled shape evolution of iron oxide nanostructures in HMTA media $\uparrow$
}

\begin{abstract}
Bin Zhao, (D) $\ddagger^{\mathrm{a}}$ Kevin M. Ryan, ${ }^{\mathrm{b}}{\text { Emmet } \mathrm{O}^{\prime} \text { Reilly }}^{\mathrm{b}}$ and Conor McCarthy ${ }^{\star a}$
This work reported an improved approach to the synthesis of iron oxide nanostructures using iron(III) chloride as the precursor and hexamethylenetetramine (HMTA) as the key auxiliary. A range of iron oxide (alkoxide) nanostructures including nanosheets, hierarchical flowers (assembled by thin nanosheets), mesoporous hollow nanospheres and solid nanospheres were obtained only by altering the reaction temperature from $180{ }^{\circ} \mathrm{C}$ to $240{ }^{\circ} \mathrm{C}$ in a single synthetic protocol. Supplementary experiments driven by reaction time were designed in order to further clarify the morphological evolution behaviors of these nanostructures, which discovered that the spherical morphology with the size of about 150-200 nm formed from the inside of micro-scaled flower-like clusters gradually by the condensing and weaving of curled nanosheets, suggesting that the hollow nanospheres were obtained consequently by the further condensation of incompact nanospheres with the assistance of the rearrangement of surfactant micelles, followed by the oriented attachment assembly and Ostwald ripening.
\end{abstract}

Received 28th March 2017 Accepted 30th April 2017

DOI: $10.1039 / \mathrm{c} 7 \mathrm{ra03603e}$

rsc.li/rsc-advances multiple iron oxide nanostructures in one synthetic procedure only by altering reaction time and temperature is clearly advantageous. To date, the synthesis of iron oxide flower like assemblies and hollow nanospheres utilizing the same synthetic route has not been reported due to their different structural properties. Iron oxide nanoflower structures are approximately 10 times larger in size than hollow iron oxide nanospheres, thereby presenting significant challenges in obtaining both structures using the same precursor and reactant ratios. ${ }^{4,6,7,10,13,14}$

Mild alkali media such as hexamethylenetetramine (HMTA) has previously been used in the synthesis of porous ZnO hollow spheres, ${ }^{18}$ flower-like $\mathrm{NiO}^{19}$ and $\mathrm{CuO}^{20}$ assemblies, highlighting HMTA as a more suitable media for the synthesis of unique morphologies in the same synthetic route, relative to urea and aqueous ammonia. ${ }^{4,6,7,17}$ Hence, in this work we highlight the benefits of using HMTA as the key reactant in the synthesis of multiple iron oxide (alkoxide) nanostructures. Iron alkoxide nanosheets, iron alkoxide nanoflowers (assembled by nanosheets), mesoporous $\mathrm{Fe}_{3} \mathrm{O}_{4}$ hollow nanospheres, $\mathrm{Fe}_{3} \mathrm{O}_{4}$ hollow nanospheres and solid $\mathrm{Fe}_{3} \mathrm{O}_{4}$ spheres can be obtained in the same experimental system by simply tuning the overall reaction temperature from 160 to $240{ }^{\circ} \mathrm{C}$. The resulting structures are characterized by XRD, SEM, TEM and HRTEM and the effect of altering reaction temperatures on subsequent nanostructure morphology is investigated.

\section{Experimental section}

\subsection{Materials}

$\mathrm{FeCl}_{3} \cdot 6 \mathrm{H}_{2} \mathrm{O}$ and ethylene glycol (EG) were purchased from Fisher Scientific. Hexamethylenetetramine (HMTA) and 
cetyltrimethylammonium bromide (CTAB) were purchased from Sigma Aldrich. All chemicals were of analytical grade and were used without further purification.

\subsection{Synthesis}

In a typical synthetic procedure, 0.006 mol $\mathrm{CTAB}$ and 0.0214 mol HMTA were dissolved in $60 \mathrm{~mL}$ ethylene glycol (EG) with ultrasonic assistance. $0.016 \mathrm{~mol} \mathrm{FeCl}_{3} \cdot 6 \mathrm{H}_{2} \mathrm{O}$ was then added under continuous stirring until fully dissolved. The solution was transferred to a $100 \mathrm{ml}$ Teflon-lined autoclave and sealed. Separate treatments were carried out at 160, 180, 200, 220 , and $240{ }^{\circ} \mathrm{C}$ for $12 \mathrm{~h}$. Once cooled to room temperature, the precipitate was washed with deionized water and absolute ethanol. A brown powder like product was obtained from the 160 and $180^{\circ} \mathrm{C}$ reactions and it was possible to separate this by centrifugation. A black powder like product was obtained at 200,220 or $240{ }^{\circ} \mathrm{C}$ and this was separated by magnetic decantation. Products were dried at $80^{\circ} \mathrm{C}$ for $12 \mathrm{~h}$ in a vacuum oven. In addition, the brown powder like product obtained at 160 or $180{ }^{\circ} \mathrm{C}$ was further calcined at $400{ }^{\circ} \mathrm{C}$ for $1 \mathrm{~h}$.

\subsection{Characterizations}

X-ray diffraction (XRD) analysis was conducted using a PANalytical X'Pert PRO MRD instrument with a $\mathrm{Cu} \mathrm{K} \alpha$ radiation source $(\lambda=1.5418 \AA)$ and an X'celerator detector. The size and morphology of iron oxide samples were characterized using field emission scanning electron microscopy (FESEM, Hitachi SU-70 system) at accelerating voltages of $10-20 \mathrm{kV}$. Powders of samples were mounted onto conductive copper tapes, which were then attached onto the surfaces of SEM brass stubs.
Samples were coated with gold by a sputtering method to minimize charging effects under FESEM imaging conditions.

Both transmission electron microscopy (TEM) and highresolution transmission electron microscopy (HRTEM) characterizations were performed using a JEOL JEM 2100F field emission microscope equipped with EDX for performing Selected Area Diffraction (SAED). To prepare the TEM specimens, the powder samples were dispersed ultrasonically in anhydrous ethanol. One drop of the suspension was placed on a carbon film supported on a copper grid and allowed to dry in air before the specimens were transferred into the microscope.

Specific surface areas were measured by nitrogen adsorption-desorption method using an ASAP 2010 Micromeritics apparatus following the BET analysis. Adsorption and desorption of $\mathrm{N}_{2}$ was performed at $-196{ }^{\circ} \mathrm{C}$. Samples had been previously outgassed by heating at $100{ }^{\circ} \mathrm{C}$ under vacuum $(3 \mathrm{~mm}$ $\mathrm{Hg}$ ). The corresponding desorption isotherm was used to determine the pore size distribution using the Barret-JoynerHalender (BJH) method.

\section{Results and discussion}

Table 1 presents an overview of the iron oxide nanostructures synthesized in HMTA media at varying temperatures. Iron alkoxide nanosheets, iron alkoxide hierarchical flowers (assembled by thin nanosheets), $\mathrm{Fe}_{3} \mathrm{O}_{4}$ hollow nanospheres with mesoporous shells, $\mathrm{Fe}_{3} \mathrm{O}_{4}$ hollow nanospheres and $\mathrm{Fe}_{3} \mathrm{O}_{4}$ solid nanospheres were obtained in the same experimental system by tuning the solvothermal temperature from 160 to $240{ }^{\circ} \mathrm{C}$. Interestingly, the iron alkoxide flower assemblies and $\mathrm{Fe}_{3} \mathrm{O}_{4}$ mesoporous hollow nanospheres differed significantly in

Table 1 An overview of the iron-contained products synthesized via HMTA approach in this work

Solvothermal treatment Products Morphologies

$160{ }^{\circ} \mathrm{C}, 12 \mathrm{~h}$

Iron alkoxide nanosheets, size: $\sim 200-400 \mathrm{~nm}$, thickness: $\sim 10-20 \mathrm{~nm}, S_{\mathrm{BET}}: 182.68 \mathrm{~m}^{2} \mathrm{~g}^{-1},{ }^{*} \mathrm{Fe}_{2} \mathrm{O}_{3}$ nanoparticles obtained, followed by calcination at $400{ }^{\circ} \mathrm{C}$

$180^{\circ} \mathrm{C}, 12 \mathrm{~h}$

$200{ }^{\circ} \mathrm{C}, 12 \mathrm{~h}$

$220{ }^{\circ} \mathrm{C}, 12 \mathrm{~h}$
Iron alkoxide nanoflowers, size: $\sim 2.5 \mu \mathrm{m}$, sheet thickness: $\sim 50 \mu \mathrm{m}$, $S_{\mathrm{BET}}: 208.99 \mathrm{~m}^{2} \mathrm{~g}^{-1},{ }^{*} \mathrm{Fe}_{2} \mathrm{O}_{3}$ flower then obtained by calcination at $400{ }^{\circ} \mathrm{C}$

$\mathrm{Fe}_{3} \mathrm{O}_{4}$ hollow nanospheres with mesoporous shells, OD: $\sim 250 \mathrm{~nm}$, shell: $\sim 30-50 \mathrm{~nm}$, pore size: $\sim 6.5 \mathrm{~nm}, S_{\mathrm{BET}}: 148.07 \mathrm{~m}^{2} \mathrm{~g}^{-1}$

$\mathrm{Fe}_{3} \mathrm{O}_{4}$ hollow nanospheres with solid shells, OD: $\sim 250 \mathrm{~nm}$, shell: $\sim 50-60 \mathrm{~nm}, S_{\mathrm{BET}}$ : $96.42 \mathrm{~m}^{2} \mathrm{~g}^{-1}$

$240{ }^{\circ} \mathrm{C}, 12 \mathrm{~h}$
$\mathrm{Fe}_{3} \mathrm{O}_{4}$ solid nanospheres size: $\sim 200 \mathrm{~nm}, S_{\mathrm{BET}}: 62.54 \mathrm{~m}^{2} \mathrm{~g}^{-1}$
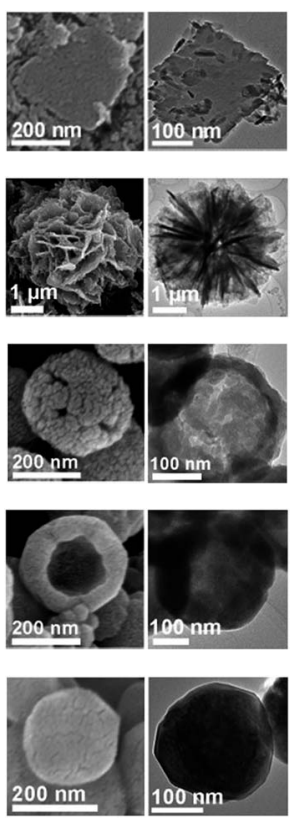
size ( $\sim 2.5$ micrometers and $\sim 250 \mathrm{~nm}$ respectively), however both nanostructures were obtained by varying the solvothermal temperature from 180 to $200{ }^{\circ} \mathrm{C}$. Additionally, $\mathrm{Fe}_{2} \mathrm{O}_{3}$ nanoparticles and flowers were obtained by calcining the iron alkoxide nanosheets and flowers at $400{ }^{\circ} \mathrm{C}$ for $1 \mathrm{~h}$, indicating that the flower-like morphology is maintained at high temperatures.

\subsection{Crystalline and morphological results}

Fig. 1a and b shows the XRD patterns of the alkoxide nanosheets and nanoflowers obtained at 160 and $180^{\circ} \mathrm{C}$ respectively. The diffraction peak located in the low-angle region $\left(\mathrm{ca} .8 .5^{\circ}\right.$ in Fig. 1a, or $c a .11^{\circ}$ in Fig. 1b) can be attributed to the iron alkoxide species as previously reported, ${ }^{3,7}$ the formula for which can be written as $\mathrm{Fe}\left(\mathrm{OCH}_{2} \mathrm{CH}_{2} \mathrm{O}\right)_{x}$. The corresponding $d$-values at $8.5^{\circ}$ and $11^{\circ}$ are 1.039 and $0.804 \mathrm{~nm}$, suggesting a reduction in $d$-value when reaction temperature is increased from 160 to $180{ }^{\circ} \mathrm{C}$. Fig. $1 \mathrm{c}$ and $\mathrm{d}$ show the nanosheet and nanoflowers products after calcination at $400{ }^{\circ} \mathrm{C}$ for $1 \mathrm{~h}$. The XRD patterns of these samples correspond well with the hematite $\mathrm{Fe}_{2} \mathrm{O}_{3}$ polymorph (JCPDS 33-0664) based on the characteristic peaks at $24.1^{\circ}(012), 33.2^{\circ}(104), 35.6^{\circ}(110), 40.9^{\circ}(113), 49.5^{\circ}(024)$ and $54.1^{\circ}(116)$.

This is further confirmed by the disappearance of the diffraction peak at about $10 \pm 2^{\circ}$ indicating the complete phase transition from iron alkoxide intermediate to the hematite $\mathrm{Fe}_{2} \mathrm{O}_{3}$ structure. Fig. $1 \mathrm{e}-\mathrm{g}$ show the XRD patterns of the $\mathrm{Fe}_{3} \mathrm{O}_{4}$ hollow and solid nanospheres obtained at 200, 220 and $240{ }^{\circ} \mathrm{C}$, respectively. The diffraction peaks at $30.1^{\circ}, 35.4^{\circ}, 43.1^{\circ}, 56.9^{\circ}$ and $62.5^{\circ}$ correspond well with the (220), (311), (400), (511) and (440) lattice planes of magnetite $\mathrm{Fe}_{3} \mathrm{O}_{4}$ (JCPDS 19-0629) without any other impurities. The diffraction intensities of XRD patterns are enhanced and the corresponding FWHMs of main peaks

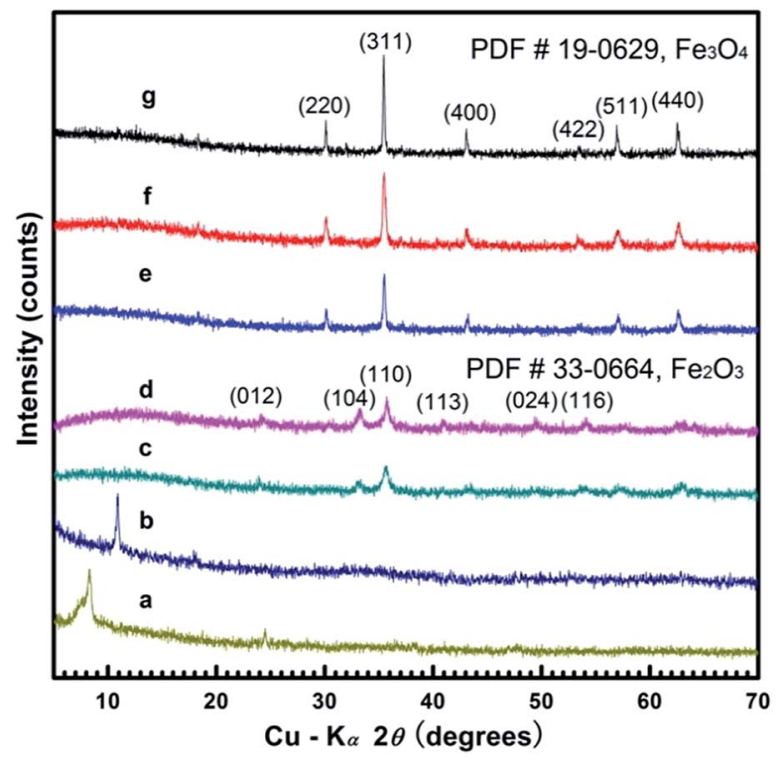

Fig. 1 XRD patterns of the products obtained under solvothermal treatment for 12 hours at $160^{\circ} \mathrm{C}(\mathrm{a}), 180^{\circ} \mathrm{C}$ (b) calcined at $400^{\circ} \mathrm{C}$ (c \& d); solvothermal treatment at $200^{\circ} \mathrm{C}$ (e), $220^{\circ} \mathrm{C}$ (f) and $240{ }^{\circ} \mathrm{C}(\mathrm{g})$. narrow with increasing temperature, thereby signifying that the crystalline grain size of product grows larger at higher temperatures, in accordance with the Scherrer equation., ${ }^{\mathbf{2}, \mathbf{6} 21}$

Fig. 2a shows an FESEM image of the uncalcined scattered nanosheets obtained at a solvothermal reaction temperature of $160{ }^{\circ} \mathrm{C}$ resulting in nanosheets with a length/width of approximately 200-400 nm. Fig. 2b shows the same nanosheets post calcination at $400{ }^{\circ} \mathrm{C}$ for $1 \mathrm{~h}$. Imaging suggests that while overall sheet-like morphology is maintained the calcination process results in nanosheet fracturing and the formation of a granular morphology with grain sizes of approximately $10-20 \mathrm{~nm}$. This is also supported by high-resolution TEM imaging (Fig. S1, ESI $\dagger$ ).

Fig. 2c shows the flower like clusters obtained by solvothermal treatment at $180{ }^{\circ} \mathrm{C}$ for $12 \mathrm{~h}$ prior to calcination. FESEM images indicate a uniform size of approximately $2.5 \mu \mathrm{m}$. FESEM images in Fig. 2d indicate flower-like clusters are formed by aggregating branches of nanosheets with an approximate thickness of $50 \mathrm{~nm}$. Fig. $2 \mathrm{e}$ and $\mathrm{f}$ indicate that the flower like clusters maintain their morphologies post calcination.

This observation is further supported by TEM imaging (Fig. S2, ESI $\dagger$ ). FESEM and TEM imaging demonstrates that the structures obtained by solvothermal treatment between 200 and $240{ }^{\circ} \mathrm{C}$ have significantly different morphologies from those obtained at lower temperatures. Fig. 3a and b show the hollow nanospheres (HNSs) obtained when the solvothermal temperature is increased to $200{ }^{\circ} \mathrm{C}$. The resulting nanospheres have an outer diameter of approximately $250 \mathrm{~nm}$, and a shell thickness of 30-50 nm (Fig. 3c) and are approximately 10 times smaller in

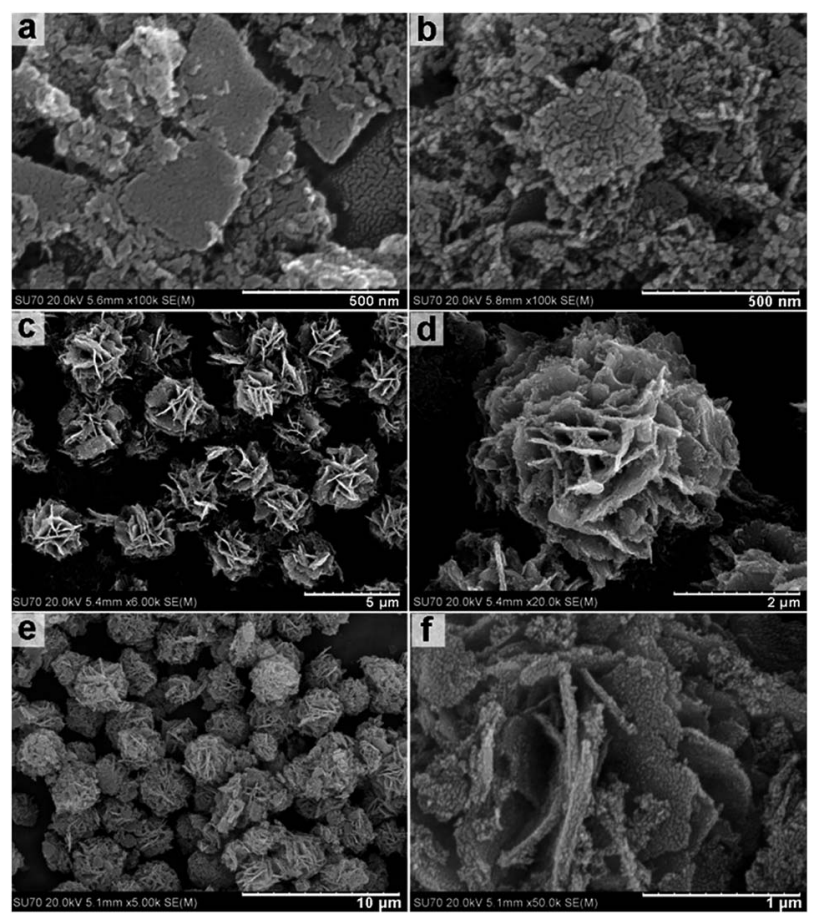

Fig. 2 FESEM images of the sample obtained under solvothermal treatment $160{ }^{\circ} \mathrm{C}$ (a) followed by calcination at $400{ }^{\circ} \mathrm{C}$ (b); FESEM images of the sample obtained at $180{ }^{\circ} \mathrm{C}$ (c \& d) followed by the calcination at $400{ }^{\circ} \mathrm{C}$ (e \& f). 

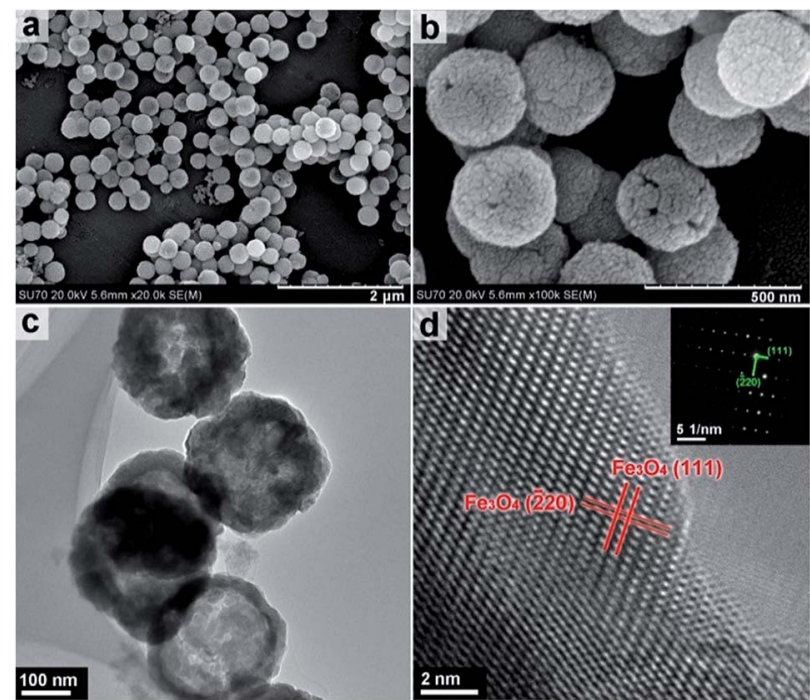

Fig. 3 FESEM ( $a \&$ b) and TEM (c) and HRTEM (d) images of the sample obtained under solvothermal treatment at $200{ }^{\circ} \mathrm{C}$. Inset in (d) the corresponding SAED pattern.

size than the flower like structures obtained at $180{ }^{\circ} \mathrm{C}$. SEM imaging in Fig. 3b indicates that the shells of spheres are assembled from crystalline grains approximately $20 \mathrm{~nm}$ in size (Fig. S3, ESI $\dagger$ ). Fig. 3d shows the HRTEM imaging of the indexed lattice fringes and corresponds well with the (111) and $(\overline{2} 20)$ planes of magnetite $\mathrm{Fe}_{3} \mathrm{O}_{4}$ polymorph. The ordered diffraction lattice shown in the corresponding SAED pattern (inset of Fig. 3d) confirms the single crystallinity of $\mathrm{Fe}_{3} \mathrm{O}_{4}$ HNSs, suggesting that the $\mathrm{Fe}_{3} \mathrm{O}_{4}$ HNSs are composed of smaller primary crystalline grains.

Increasing the overall reaction temperature to $220^{\circ} \mathrm{C}$ results in hollow nanospheres of approximately $250 \mathrm{~nm}$ in diameter. Fig. 4a and c show the TEM imaging of the hollow nanospheres

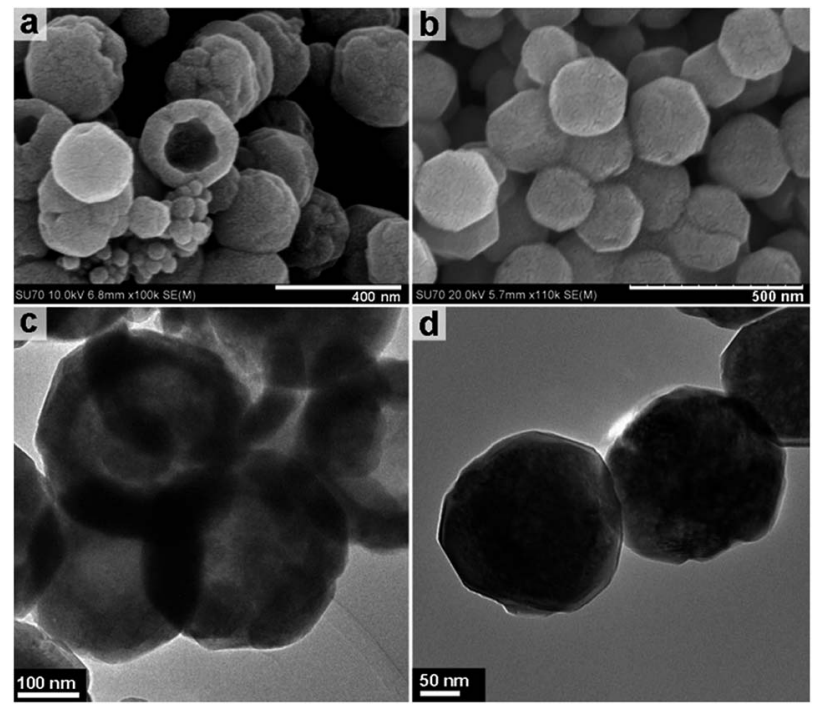

Fig. 4 FESEM and TEM images of the sample obtained under solvothermal treatment at $220^{\circ} \mathrm{C}\left(\mathrm{a} \& \mathrm{c}\right.$ ) and $240{ }^{\circ} \mathrm{C}$ (b \& d). and highlight the hollow spherical construction with a shell thickness of 50-60 $\mathrm{nm}$. Increasing the solvothermal temperature from 200 to $220{ }^{\circ} \mathrm{C}$ increases the overall shell thickness and in some cases causes partial breaking of the spheres to form a cup-like morphology or hollow hemispheres. Fig. $4 \mathrm{~b}$ and $\mathrm{d}$ demonstrate that increasing the reaction temperature to $240{ }^{\circ} \mathrm{C}$ results in solid spheres with a uniform size of approximately $250 \mathrm{~nm}$. HRTEM images and corresponding SAED patterns (Fig. S4, ESI $\dagger$ ) confirm that both the hollow and solid nanospheres are magnetite $\mathrm{Fe}_{3} \mathrm{O}_{4}$ polymorphs with well-defined lattice fringes.

\subsection{Porosity results}

Fig. 5 shows the $\mathrm{N}_{2}$ adsorption-desorption isotherms and Barret-Joyner-Halenda (BJH) pore size distribution plots for each of the different morphologies. The nitrogen adsorption isotherms in Fig. 5a should be of type III, ${ }^{22,23}$ but most of them present high absorbed volume $\left(>300 \mathrm{~cm}^{3} \mathrm{~g}^{-1}\right)$ and obvious hysteresis loops at higher-pressure region. Specifically, a distinct hysteresis loop for the products obtained at $160{ }^{\circ} \mathrm{C}$ was observed in the range of 0.7-1.0 $P / P_{0}$, which belonged to the H3 type. ${ }^{24,25}$ The red curve (nanosheets formed at $160^{\circ} \mathrm{C}$ ) shown in Fig. 5b exhibited a relatively broad porous distribution below $20 \mathrm{~nm}$. One possible reason for this may be due to the effect of pores on overlapping plate like nanosheets as observed in SEM and TEM imaging. A hysteresis loop of the $\mathrm{H} 4$ type was observed for the flower-like iron alkoxide product and the corresponding
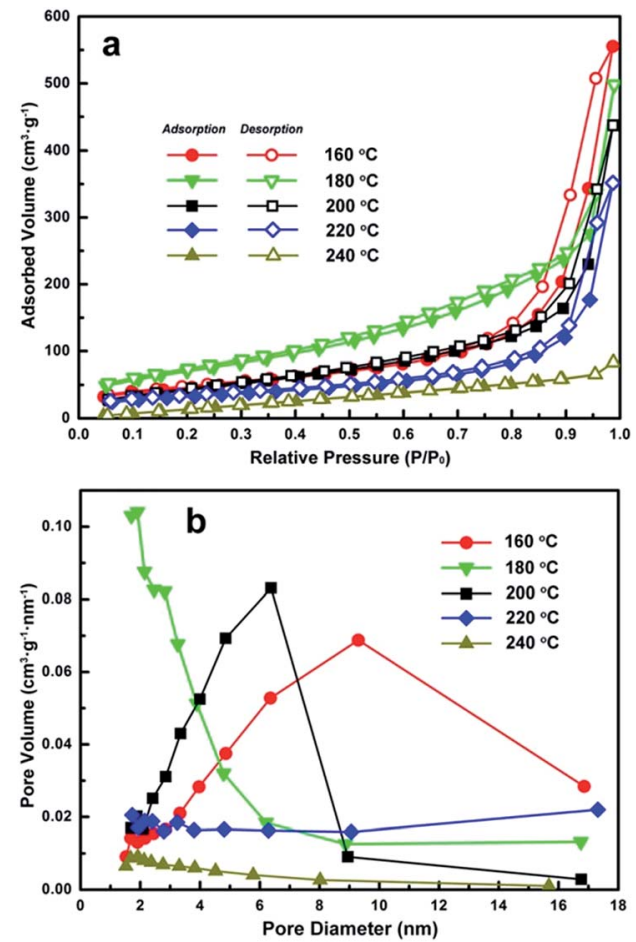

Fig. $5 \mathrm{~N}_{2}$ adsorption/desorption isotherms (a) and pore size distributions (b) for as-prepared products obtained under solvothermal treatment at 160,180, 200, 220 and $240{ }^{\circ} \mathrm{C}$ without further calcinations. 
pore distribution shifted below $6 \mathrm{~nm}$ indicating that the product consists of slit pores accumulated by laminar sheets with decreased spacing., ${ }^{\mathbf{3 , 4 2}}$ This phenomenon further confirms the formation of flower-like clusters assembled by aggregating nanosheets.

The $\mathrm{Fe}_{3} \mathrm{O}_{4}$ hollow nanospheres obtained at $200{ }^{\circ} \mathrm{C}$ also demonstrated a typical hysteresis loop of the $\mathrm{H} 3$ type in the range of 0.5-1.0 $P / P_{0}$. Absorption/Desorption isotherms for the hollow nanospheres obtained at $200{ }^{\circ} \mathrm{C}$ (Fig. 5b black curve) show a sharp peak at $6.5 \mathrm{~nm}$ indicating an increase in mesoporous characteristics. This can be attributed to the formation of the primary crystalline grains that in turn constitute the shells of $\mathrm{Fe}_{3} \mathrm{O}_{4}$ hollow nanospheres as highlighted in Fig. 3. The hollow nanospheres obtained at $220{ }^{\circ} \mathrm{C}$ did not demonstrate any porous characteristics. The pore volume of the solid nanospheres obtained at $240{ }^{\circ} \mathrm{C}$ is further lower than that of the porous spheres obtained at $220^{\circ} \mathrm{C}$, which is consistent with the morphologies observed in the SEM and TEM images of Fig. 4.

Meanwhile, the $S_{\mathrm{BET}}$ specific surface areas of the products obtained under solvothermal treatment at 160, 180, 200, 220 and $240{ }^{\circ} \mathrm{C}$ are $182.68,208.99,148.07,96.42$ and $62.54 \mathrm{~m}^{2} \mathrm{~g}^{-1}$, respectively. The product obtained at $160{ }^{\circ} \mathrm{C}$ has the second largest specific surface areas among all products probably because of the disordered accumulation of nanosheets with considerable thin thickness. The product obtained at $180^{\circ} \mathrm{C}$ has the largest $S_{\mathrm{BET}}$ value $\left(208.99 \mathrm{~m}^{2} \mathrm{~g}^{-1}\right)$ probably due to the hierarchical flower-like morphologies assembled by 2D nanosheets, which optimizes its accumulation status better than the nanosheets products. Then the $S_{\mathrm{BET}}$ specific surface areas decrease severely after the formation of $\mathrm{Fe}_{3} \mathrm{O}_{4}$ nanostructures. This is most likely due to the collapse of the alkoxide based flower-like assemblies and the formation of $\mathrm{Fe}_{3} \mathrm{O}_{4}$ crystalline structures. The $\mathrm{Fe}_{3} \mathrm{O}_{4}$ product obtained at $200{ }^{\circ} \mathrm{C}$ still has comparatively large specific surface areas $\left(S_{\mathrm{BET}}=148.07 \mathrm{~m}^{2}\right.$ $\mathrm{g}^{-1}$ ), which should be contributed from its mesoporous feature and hollow spherical morphology together. The $S_{\text {BET }}$ specific surface areas decrease severely from 200 to $240{ }^{\circ} \mathrm{C}$, which should be resulted by the disappearances of mesoporous feature and hollow spherical morphology progressively.

\subsection{Formation mechanism}

To further investigate the formation mechanism and investigate the effect of reaction time on subsequent structure morphology a series of synthetic experiments were performed whereby the temperature was maintained at $200{ }^{\circ} \mathrm{C}$ for 3,6 and $9 \mathrm{~h}$, respectively.

Fig. 6 shows the XRD results for the structures obtained after $3,6,9$, and $12 \mathrm{~h}$ solvothermal treatment and indicate that crystal growth occurs from metastable iron alkoxides to more stable polymorphs of magnetite $\mathrm{Fe}_{3} \mathrm{O}_{4}$ as per Ostwald's step rule. ${ }^{21,26-29}$ Fig. 6a shows an amorphous product is obtained after $3 \mathrm{~h}$ of reaction time. The diffraction peak at about $8.5^{\circ}$ in Fig. $6 \mathrm{~b}$ (marked as " $\Delta$ ") corresponds well with the XRD pattern of the iron alkoxide nanosheets in Fig. 1a, indicating that the iron alkoxide intermediates are formed after an overall reaction time of $6 \mathrm{~h}$. The product obtained at $9 \mathrm{~h}$ (Fig. 6c) exhibits the

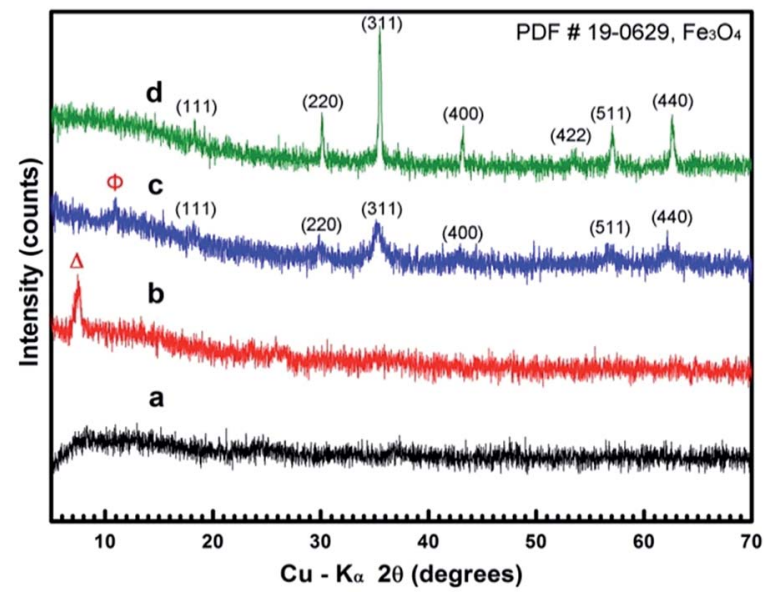

Fig. 6 XRD patterns of samples obtained in the typical solvothermal procedure at $200^{\circ} \mathrm{C}$ for 3 (a), 6 (b), 9 (c) and $12 \mathrm{~h}$ (d).

standard $\mathrm{Fe}_{3} \mathrm{O}_{4}$ polymorph with low crystallinity co-existing with a weak diffraction peak at about $11^{\circ}$ (marked as " $\Phi$ "). This corresponds well with the iron alkoxide flower-like assemblies in Fig. 1b. Finally, the product obtained after $12 \mathrm{~h}$ (Fig. 6d) displays a typical pattern consistent with magnetite $\mathrm{Fe}_{3} \mathrm{O}_{4}$.

Similar to the reported layered sodium titanate, ${ }^{21,28,29}$ the iron alkoxides herein with a diffraction peak close to $10^{\circ}$ should contain wide lattice spacing (ca. $1 \mathrm{~nm}$ ), in which iron atoms are responsible for the basic units of each layer and the glycolates of differing chain length are responsible for the interlayer spacing. Iron alkoxides with a diffraction peak at $11^{\circ}$ should have higher condensation than that at about $8.5^{\circ}$. Results indicate that the condensation process from $\mathrm{Fe}\left(\mathrm{OCH}_{2} \mathrm{CH}_{2} \mathrm{O}\right)_{x}$ to iron oxide can be performed thermodynamically (e.g. increasing temperature from 180 to $200{ }^{\circ} \mathrm{C}$ ), or time dependently (e.g. prolonging the duration time from 6 to $9 \mathrm{~h}$ at $200{ }^{\circ} \mathrm{C}$ ), resulting in the shift of diffraction peak to higher angles and corresponding growth of nanosheets.

Fig. 7 shows the FESEM and HRTEM images of the structures obtained after 3, 6 and $9 \mathrm{~h}$ of solvothermal treatment at $200{ }^{\circ} \mathrm{C}$. The FESEM image of the product obtained after a reaction time of $3 \mathrm{~h}$ (Fig. 7a) displays only a sheet-like morphology and is consistent with amorphous XRD pattern obtained in Fig. 6a. Fig. $6 \mathrm{~b}$ shows that nanosheets with a thickness of approximately 10-20 $\mathrm{nm}$ are obtained after $6 \mathrm{~h}$ of reaction time. It is upon increasing the reaction time from 6 to $9 \mathrm{~h}$ that the most significant changes in morphology are observed. Fig. 7c shows the FESEM images of the product obtained after $9 \mathrm{~h}$ of solvothermal treatment at $200{ }^{\circ} \mathrm{C}$. The images show sheet and spherical shaped structures of approximately 150-200 $\mathrm{nm}$ in size. The image suggests that the spheres have grown from within the nanosheet assemblies. This is further confirmed by the TEM and HRTEM imaging shown in Fig. 7d-f. Fig. 7f shows that the incompact nanospheres consist of aggregated nanograins ranging in size from $2-3 \mathrm{~nm}$ in imperfect oriented attachment; this is also confirmed by HRTEM imaging (Fig. S5, ESI $\dagger$ ). The corresponding SAED pattern (inset Fig. 7f) highlights that the nanocrystalline nature of $\mathrm{Fe}_{3} \mathrm{O}_{4}$ exists in random 


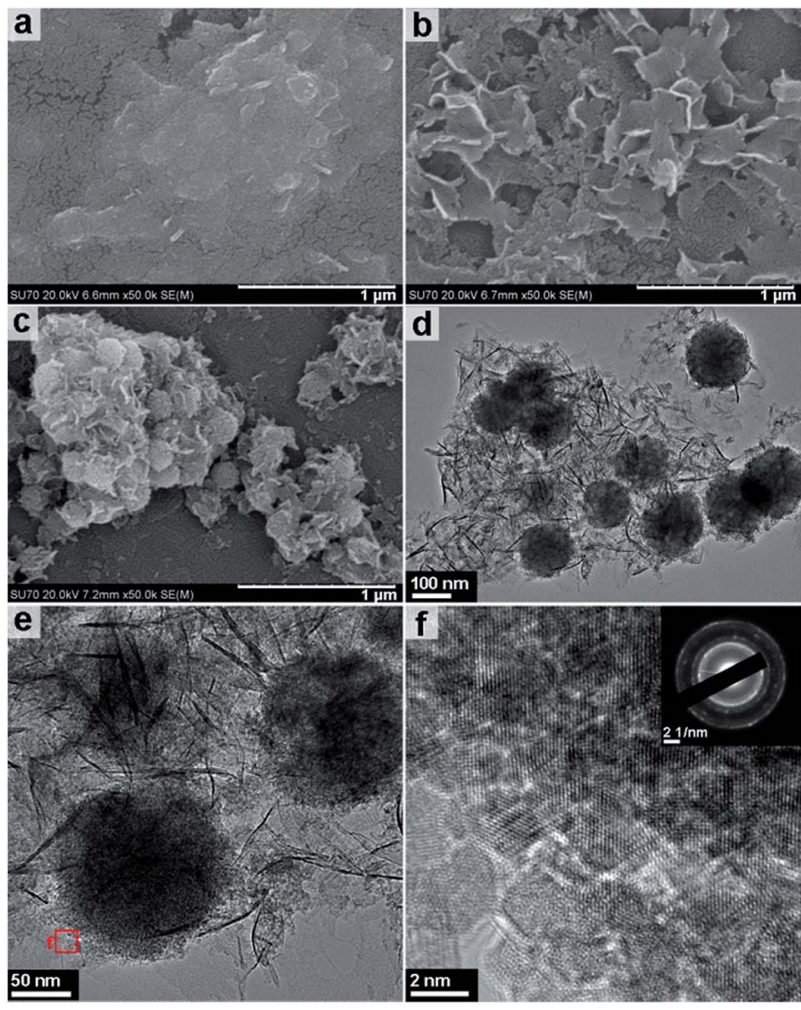

Fig. 7 FESEM images of the sample obtained under solvothermal treatment at $200^{\circ} \mathrm{C}$ for 3 (a), 6 (b) and $9 \mathrm{~h}$ (c \& d); TEM images (d, e \& f) of the sample obtained under solvothermal treatment at $200{ }^{\circ} \mathrm{C}$ for $9 \mathrm{~h}$. Inset in (f) the corresponding SAED pattern.

orientation. The formation status of the spheres inside the nanosheet assemblies is further observed by supplementary SEM results (Fig. S6, ESI $\dagger$ ).

Based on SEM and HRTEM imaging a schematic of the proposed morphological evolution herein is presented in Scheme 1. Self-assembly, oriented attachment and Ostwald ripening were commonly employed in previous works to elucidate the formation mechanism of either flower-like or hollow spherical morphologies, which were suitable for not only iron oxide $^{1-3,7-14,24,27,30-33}$ but also various kinds of metal oxide, metal alloys or non-metal $\mathrm{SiO}_{2}$ nanostructures. ${ }^{28,29,34-36}$ These theories/ mechanisms are mostly based on the same intrinsic assumption that the crystal growth and morphological evolution tend towards a thermodynamic equilibrium regime in the reaction process. In general, the crystalline/morphological transition is driven by the reduction of overall lattice/surface energy. ${ }^{34,35}$

Our observations suggest that during the initial period of solvothermal treatment $\mathrm{Fe}^{3+}$ ions react with the solvent EG (Scheme 1a) to form the primary nuclei $\mathrm{Fe}\left(\mathrm{OCH}_{2} \mathrm{CH}_{2}\right.$ O) $x^{3,7,13,14,17,33}$ The reduction of the overall surface energy by elimination of the interface drives the oriented attachment, thus the lattice planes with higher surface energy are preferentially eliminated in the process of crystal growth..$^{31,37,38}$ This is followed by self-assembly to form the $2 \mathrm{D}$ nanosheets with the assistance of surfactant CTAB (Scheme 1b). During this process it is possible the CTAB effectively reduces the surface energy toward the vertical axis of the sheet plane, resulting in an

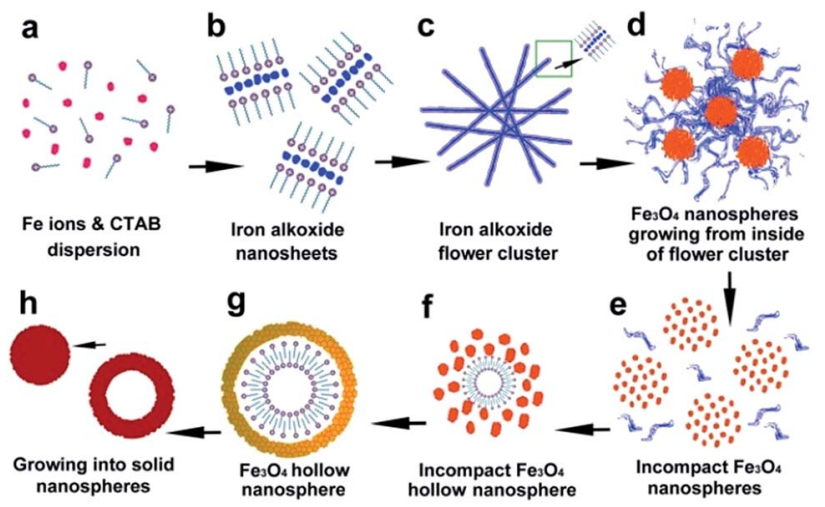

Scheme 1 Schematic illustrations of the morphological evolution process between tailored iron oxide (alkoxide) nanostructures.

$\mathrm{Fe}\left(\mathrm{OCH}_{2} \mathrm{CH}_{2} \mathrm{O}\right)_{x}$ intermediate with a layered crystalline structure and XRD peak at $8-8.5^{\circ}$.

When the highest energy interface was eliminated by oriented attachment, the subordinate high-energy interface became the highest energy interface; thus, the oriented attachment would take place sequentially on these subordinate interfaces. ${ }^{38}$ When the 2D nanosheets reached a certain size, the iron alkoxide nanosheets would spontaneously crimp into curled selfassemblies (Scheme 1c and d). This curling phenomenon has also been observed in the case of layered titanate nanosheets. ${ }^{39}$ This behavior is possibly due to continued oriented attachment and also the upheaval of internal stress during further condensation of iron alkoxide layers (XRD peak shifts from $c a .8-8.5^{\circ}$ to $c a .11^{\circ}$ ). If this process were maintained at suitable reaction conditions, $\left(\right.$ e.g. $\left.180^{\circ} \mathrm{C}, 12 \mathrm{~h}\right)$ the thickness would change from approximately $10-20 \mathrm{~nm}$ to $c a$. $50 \mathrm{~nm}$ due to the subordinate oriented attachment and the sheet assemblies would further grow into the flower-like clusters such as those presented in Fig. 2.

It is likely that the incompact nanospheres grow from the inside flower-like clusters (Scheme 1d) as a result of condensing and weaving of the nanosheets. Based on the images observed in Fig. 7, the iron oxide primary nucleus with a grain size of approximately $2-3 \mathrm{~nm}$ are initially generated by the condensation of iron alkoxides inside the flower-like assemblies. Subsequent aggregation of the nuclei leads to the formation of several incompact spheres at numerous locations on the flower like assemblies, followed by Ostwald ripening., ${ }^{2,10,27,30,33}$ Continued condensation results in the formation of larger crystalline grains, during which the surfactant micelles located on the surface of $\mathrm{Fe}_{3} \mathrm{O}_{4}$ primary nuclei rearrange. Rearrangement of these free surfactant micelles occurs between $9 \mathrm{~h}$ and $12 \mathrm{~h}$ at $200{ }^{\circ} \mathrm{C}$ reaction temperature resulting in the formation of the hollow spherical morphology as shown in Scheme 1g. Further condensation results in thickening of the nanosphere shells and the formation of solid spheres (Scheme $1 \mathrm{~h}$ ).

\section{Conclusions}

In conclusion, we have demonstrated a facile procedure for the synthesis of a variety of iron oxide (alkoxide) nanostructures 
using a single experiment approach that only needs to change the temperature. Morphologies including nanosheets, nanoflowers, hollow and solid nanospheres can be reproducibly obtained simply by varying the reaction temperature between 160 and $240{ }^{\circ} \mathrm{C}$. SEM and HRTEM imaging demonstrated that the morphological evolution of the nanostructures follows previously reported oriented attachment assembly and Ostwald ripening mechanisms. Hollow and solid nanospheres were subsequently obtained by further condensation of incompact nanospheres. Facile approaches to the synthesis of iron alkoxide nanostructures such as those presented in this work can underpin the use of these materials in high performance applications such as magnetic data storage, biosensing and drug delivery.

\section{Acknowledgements}

This work was supported by Science Foundation Ireland (SFI) under Investigators Project (IvP) 13/IA/1833, "Fastener-less Joining Technologies for High Performance Hybrid Composites-Metal Structures".

\section{Notes and references}

1 Q. L. He, T. T. Yuan, S. Y. Wei, N. Haldolaarachchige, Z. P. Luo, D. P. Young, A. Khasanov and Z. H. Guo, Angew. Chem., Int. Ed., 2012, 51, 8842-8845.

2 J. B. Lian, X. C. Duan, J. M. Ma, P. Peng, T. Kim and W. J. Zheng, ACS Nano, 2009, 3, 3749-3761.

3 X. H. Ma, X. Y. Feng, C. Song, B. K. Zou, C. X. Ding, Y. Yu and C. H. Chen, Electrochim. Acta, 2013, 93, 131-136.

4 H. H. Niu, S. W. Zhang, Q. Ma, S. X. Qin, L. Wan, J. Z. Xu and S. D. Miao, RSC Adv., 2013, 3, 17228-17235.

5 K. Cheng, S. Peng, C. J. Xu and S. H. Sun, J. Am. Chem. Soc., 2009, 131, 10637-10644.

6 K. Cheng, Z. Y. Sun, Y. M. Zhou, H. Zhong, X. K. Kong, P. Xia, Z. Guo and Q. W. Chen, Biomater. Sci., 2013, 1, 965-974.

7 X. A. Li, B. Zhang, C. H. Ju, X. J. Han, Y. C. Du and P. Xu, J. Phys. Chem. C, 2011, 115, 12350-12357.

8 B. Zhao, M. Hardiman, K. M. Ryan, E. O'Reilly and C. McCarthy, CrystEngComm, 2016, 18, 6096-6101.

9 W. Yan, H. Q. Fan, Y. C. Zhai, C. Yang, P. R. Ren and L. M. Huang, Sens. Actuators, B, 2011, 160, 1372-1379.

10 X. Zhang, M. Lin, X. Y. Lin, C. T. Zhang, H. T. Wei, H. Zhang and B. Yang, ACS Appl. Mater. Interfaces, 2014, 6, 450-458.

11 Y. B. Liu, Y. Q. Wang, S. M. Zhou, S. Y. Lou, L. Yuan, T. Gao, X. P. Wu, X. J. Shi and K. Wang, ACS Appl. Mater. Interfaces, 2012, 4, 4913-4920.

12 B. Karagoz, J. Yeow, L. Esser, S. M. Prakash, R. P. Kuchel, T. P. Davis and C. Boyer, Langmuir, 2014, 30, 10493-10502.

13 J. J. Zhang, Y. L. Chen, Y. F. Sun, T. Huang and A. S. Yu, RSC Adv., 2013, 3, 20639-20646.
14 X. Y. Li, Z. J. Si, Y. Q. Lei, X. N. Li, J. K. Tang, S. Y. Song and H. J. Zhang, CrystEngComm, 2011, 13, 642-648.

15 S. W. Cao, Y. J. Zhu, M. Y. Ma, L. Li and L. Zhang, J. Phys. Chem. C, 2008, 112, 1851-1856.

16 B. L. Lv, Y. Xu, D. Wu and Y. H. Sun, CrystEngComm, 2011, 13, 7293-7298.

17 M. Khosravi and S. Azizian, Adv. Powder Technol., 2014, 25, 1578-1584.

18 N. Tripathy, R. Ahmad, H.-S. Jeong and Y.-B. Hahn, Inorg. Chem., 2012, 51, 1104-1110.

19 S.-I. Kim, J.-S. Lee, H.-J. Ahn, H.-K. Song and J.-H. Jang, ACS Appl. Mater. Interfaces, 2013, 5, 1596-1603.

20 M. Vaseem, A. Umar, S. H. Kim and Y.-B. Hahn, J. Phys. Chem. C, 2008, 112, 5729-5735.

21 B. Zhao, F. Chen, Y. C. Jiao and J. L. Zhang, J. Mater. Chem., 2010, 20, 7990-7997.

22 S. Brunauer, L. S. Deming, W. E. Deming and E. Teller, J. Am. Chem. Soc., 1940, 62, 1723-1732.

23 K. S. W. Sing, D. H. Everett, R. A. W. Haul, L. Moscou, R. A. Pierotti, J. Rouquerol and T. Siemieniewska, Pure Appl. Chem., 1985, 57, 603-619.

24 Z. Li, H.-F. Fei, Y. Tan, X. Z. Zhang, Z. Xie and Z. Zhang, RSC Adv., 2015, 5, 38093-38099.

25 Z. Ali, L. Tian, P. Zhao, B. Zhang, A. Nisar, X. Li, H. Zhang and Q. Zhang, RSC Adv., 2015, 5, 92449-92455.

26 R. A. V. Santen, J. Phys. Chem., 1984, 88, 5768-5769.

27 W. Ostwald, Z. Phys. Chem., 1897, 22, 289-330.

28 B. Zhao, F. Chen, Q. W. Huang and J. L. Zhang, Chem. Commun., 2009, 34, 5115-5117.

29 B. Zhao, L. Lin and D. He, J. Mater. Chem. A, 2013, 1, 16591668.

30 J. F. Banfield, S. A. Welch, H. Z. Zhang, T. T. Ebert and R. L. Penn, Science, 2000, 289, 751-754.

31 X. F. Yang, J. X. Fu, C. J. Jin, J. Chen, C. L. Liang, M. M. Wu and W. Z. Zhou, J. Am. Chem. Soc., 2010, 132, 14279-14287.

32 V. M. Yuwono, N. D. Burrows, J. A. Soltis and R. L. Penn, J. Am. Chem. Soc., 2010, 132, 2163-2165.

33 B. X. Wang, Y. C. Yin, C. J. Liu, S. S. Yu and K. Z. Chen, Dalton Trans., 2013, 42, 10042-10055.

34 J. W. Mullin, Crystallization, Butterworth-Heinemann, Oxford, UK, 4th edn, 2001.

35 M. Wang, B. Zhao, S. Xu, L. Lin, S. Liu and D. He, Chem. Commun., 2014, 50, 930-932.

36 M. Wang, Q. Zeng, B. Zhao and D. He, J. Mater. Chem. A, 2013, 1, 11465-11472.

37 R. L. Penn and J. F. Banfield, Science, 1998, 281, 969-971.

38 H. L. Xu, W. Z. Wang, W. Zhu, L. Zhou and M. L. Ruan, Cryst. Growth Des., 2007, 7, 2720-2724.

39 B. Zhao, F. Chen, X. Gu and J. Zhang, Chem.-Asian J., 2010, 5, 1546-1549. 